\title{
Augmentative Effects of Working Memory Training on Behavioral Problems and Parental Stress in Medicated Children and Adolescents with Attention-Deficit Hyperactivity Disorder
}

\author{
Eun Kyung Lee, Hye Sun Kim, and Hanik K. Yoo \\ Seoul Brain Research Institute, Seoul, Korea
}

\section{약물치료 중인 주의력결핍 과잉행동장애 아동 청소년에서 작업기억훈련이 행동문제와 부모 스트레스에 미치는 부가적 효과}

이은경, 김혜선, 유한익

서울뇌과학연구소

\begin{abstract}
Objectives: Executive dysfunctions including working memory deficit have been suggested to be one of the major neuropsychological etiologies of attention-deficit hyperactivity disorder (ADHD). The purpose of this study was to investigate the augmentative effects of working memory training on the behavioral problems, quality of life, and parental stress of medicated children with ADHD.

Methods: Twenty-five children with ADHD, aged 9 to 19 years, who were being treated with ADHD medication, were included. The participants were trained with a commercially available and computerized working memory program $\left(\operatorname{Cogmed}{ }^{\circledR}\right)$ for 5 weeks without any alteration of their medication. The Child Behavior Checklist (CBCL), KIDSCREEN-52 quality of life measure, and Parenting Stress IndexShort Form (PSI-SF) were administered before training, and 4 weeks and 7 months after training, respectively.

Results: After completing the training, the anxiety/depression, social problems, thought problems, attention problems, aggressive behavior, and externalizing problems scores in the CBCL were significantly reduced. The score on the Parent-child dysfunctional interaction in the PSI-SF was also decreased. However, the scores related to the quality of life were not changed. These changes were still observed 7 months after the training.

Conclusion: Cogmed working memory training can be a promising training option for the additional improvement of behavioral problems and parental stress in medicated children with ADHD.
\end{abstract}

Key Words: Working memory training; Cogmed; Attention-deficit hyperactivity disorder; Behavioral problem; Parental stress.

Received: October 20, 2016 / Revision: January 18, 2017 / Accepted: February 18, 2017

Address for correspondence: Hanik K. Yoo, Seoul Brain Research Institute, 10 Gangbyeonyeok-ro 4-gil, Gwangjin-gu, Seoul 05116, Korea Tel: +82-2-452-2150, Fax: +82-2-6280-2163, E-mail: hanikyoo@gmail.com

서 론

주의력결핍 과잉행동장애(attention-deficit hyperactivity disorder, ADHD)는 정상발달 수준에서 벗어난 주의력 저하, 과잉행동 및 충동성이 핵심증상인 정신과 질환으로 학업, 대 인관계, 정서적인 어려움으로 인한 유의한 기능 저하를 일으키 는 질환이다. $\mathrm{ADHD}$ 는 소아청소년정신과에 내원한 아동들 중

This is an Open Access article distributed under the terms of the Creative Commons Attribution Non-Commercial License (http://creativecommons.org/licenses/by-nc/4.0) which permits unrestricted non-commercial use, distribution, and reproduction in any medium, provided the original work is properly cited.
30 50\%에 해당되고, 유병률은 학령기 아동의 3 7\%이며, 남 아에게서 3 4배 흔하다.1) 보통 12세 이전에 발병하고, 37 85\% 가 청소년 및 성인기에도 증상이 지속된다.)

$\mathrm{ADHD}$ 는 전두엽과 관련된 여러 뇌구조에 의해 매개되는 실행기능의 문제, 특히 작업기억력의 결함과 관련이 깊다. ${ }^{2}$ 작 업기억력은 짧은 시간 동안 정보에 대한 기억을 유지하며 이를 조작할 수 있는 능력으로, 억제 조절과 선택적, 초점적 주의력 기능에 관여하기 때문에 $\mathrm{ADHD}$ 와 밀접하게 연관되어 있다.3) $\mathrm{ADHD}$ 는 전두엽 기능 저하와 질적으로 유사한 증상을 보이 며, 정상군에 비해 작업기억력검사에서 낮은 수행을 보인다. ${ }^{4}$ 
$\mathrm{ADHD}$ 아동의 치료는 현재 신경생화학적 이상에 기초한 약물치료가 우선적으로 권고된다. 가장 많이 사용되고 있는 methylphenidate에 의해 약 70 80\% 정도에서 효과가 나타나 며, 특히 ADHD의 핵심증상이 개선된다.5) 그러나 약물치료에 반응하지 않는 사례도 있고, 약물이 효과적인 환자들도 부작 용이나 약물순응 문제로 인해 지속적인 사용이 어려운 경우도 있다.) 또한 약물치료, 행동치료, 약물과 행동치료의 병합치료, 지역사회치료를 비교한 Multimodal Treatment Study of Children with ADHD 결과를 보면, 치료 후 14개월 시점에서 는 $\mathrm{ADHD}$ 핵심증상에 대해 약물치료와 병합치료 그룹이 다 른 그룹에 비해 유의하게 좋은 효과를 보였고 학업성적에서 병합치료 그룹이 다른 그룹들을 능가하는 결과를 보였으나, 3,8 년 후 시점에서는 모든 평가항목들에서 네 그룹에 차이가 없었다. ${ }^{7-9)}$ 이는 비약물치료 단독으로는 ADHD 핵심증상을 호전시킬 수 없지만, 약물치료 역시 장기적인 효과가 단기 효과 보다 불확실하며, 특히 $\mathrm{ADHD}$ 핵심증상 외의 다른 복잡한 문 제를 해결하는 데는 한계가 있음을 시사한다. ${ }^{10}$

이러한 이유로 인해 $\mathrm{ADHD}$ 환자를 대상으로 비약물적 중재 를 계속 시도해 왔다. 최근 가장 활발이 시도되는 접근법으로 는 인지행동치료가 있는데, $\mathrm{ADHD}$ 아동들의 행동문제의 감소 및 대인관계 문제 개선 효과가 보고되었다. ${ }^{11}$ 하지만 $\mathrm{ADHD}$ 의 핵심증상과 인지적 결함 자체에 대한 효과 검증은 아직까지 부족한 상태이다.12) 또한 뇌의 전기적 활동과 직접적으로 관련 되어 있는 뉴로피드백훈련이 대안으로 제시되고 있으나, 이중 맹검위약대조 연구 결과가 미미하며 아직까지 확정적인 효과 검증이 이루어지지 못한 상태이다. ${ }^{13)}$

$\mathrm{ADHD}$ 는 작업기억력의 결손이 핵심적인 신경심리학적 문제 라는 가설을 바탕으로 한 비약물적 중재로서 코그메드 작업기 억력훈련(Cogmed Working Memory Training, CWMT)에 대 한 연구가 지속되어 왔다. CWMT는 비교적 잘 고안된 연구들 에서 이미 효과가 검증되었고, ${ }^{14)} \mathrm{ADHD}$ 아동의 작업기억력과 관련된 뇌 영역의 활성도, 뇌 영역들 간 기능적 연결성, 도파민 수용체의 밀집도 등 뉴런적 수준에 변화를 주어 ${ }^{15,16)}$ 훈련의 직 접 효과(direct effect) 외에도 전이효과(transfer effect)를 나타 내는 것으로 보인다. 또한 유전자와의 연관성 연구들도 보고 되어, ${ }^{17,18)}$ 유전자 연관성-뇌의 생화학적 및 구조적 변화-신경 인지적 변화-임상증상 및 기능의 변화까지 연결된 아주 일관된 연구 결과를 보고해 왔다. 가장 선구적인 임상연구로서, Klingberg 등 ${ }^{19)}$ 이 평균 11세 $\mathrm{ADHD}$ 아동 14명에게 컴퓨터기반 작 업기억력훈련을 매일 25분씩 25일간 적용하여, 시공간적 작업 기억력, 행동 억제능력, 과제에 대한 반응시간에서 훈련의 효 과를 처음으로 확인하였다. 이후 Klingberg 등이이 7 12세 $\mathrm{ADHD}$ 아동 53명에게 훈련을 실시한 결과, 훈련받은 작업기
억력뿐 아니라 훈련받지 않은 작업기억력, 행동 억제능력, 추 론 능력에서 향상이 있었고, 부모평정 척도에서는 부주의와 과잉행동/충동성의 모든 영역에서 감소를 보였으며, 이 효과 는 3 개월 후까지 지속되었다. 이 외에도 비언어적·언어적 작 업기억력, 단순저장능력을 통제한 작업기억력, 복합적 작업기 억력의 향상이 최장 1 년까지 지속되고, 정신자극제를 복용하 지 않는 $\mathrm{ADHD}$ 아동에서도 언어적 작업기억력이 향상되며, 정신자극제를 단독으로 사용하는 경우보다 실행기능에 광범 위한 영향을 미치는 것으로 보고된다. ${ }^{21-23)}$ 또한 과제 이탈 행동 (off-task behavior)의 감소, ${ }^{24)}$ 지시 수행의 향상, ${ }^{25}$ 읽기· 수학 영어 능력의 증진 ${ }^{21}$ 이 훈련 직후 또는 지연된 효과(delayed effect)로서 보고되어 최장 8개월까지 효과가 지속되었고, $\mathrm{CWMT}$ 가 $\mathrm{ADHD}$ 아동의 학업적 수행을 간접적으로 변화시키 는 기제로 시사되었다.

이처럼 $\mathrm{CWMT}$ 가 $\mathrm{ADHD}$ 아동의 작업기억력을 개선하여 부주의 증상뿐 아니라 전반적인 행동 및 기능에 영향을 미칠 것으로 예상되나, 현재까지는 $\mathrm{ADHD}$ 아동의 작업기억력, 핵심 증상과 학업적 영역에 대한 효과에만 연구가 집중되어 있으며, 문제행동이나 삶의 질과 같은 $\mathrm{ADHD}$ 환자의 이차적 문제들 이나 아동을 돌보는 부모의 스트레스에 대한 효과 연구는 거 의 없었다. 또한 실제 임상에서는 대부분의 $\mathrm{ADHD}$ 환자들이 이미 약물치료를 받고 있기 때문에, 작업기억훈련이 이미 약물 치료에 의해 어느 정도 증상이 좋아진 환자들에게 부가적인 효과를 보일 수 있는지를 조사하는 연구가 필요하다. 이에 본 연구에서는 약물치료에 부분적인 반응을 보였던 $\mathrm{ADHD}$ 아 동 및 청소년에게 CWMT를 추가적으로 실시한 후, 문제행동, 삶의 질, 부모의 양육스트레스에 미치는 영향을 조사하였다.

\section{방 법}

\section{대 상}

서울 소재 소아청소년정신과 외래에 주의력 문제로 내원한 $\mathrm{ADHD}$ 아동 및 청소년 중 소아청소년정신과 전문의가 $\mathrm{DSM}-$ $\mathrm{IV}-\mathrm{R}$ 에 의거해 $\mathrm{ADHD}$ 로 진단한 환자를 대상으로 하였다. 이 러한 진단은 병력 청취 및 정신과적 진찰, 보조적인 심리검사 결과를 종합해서 내려졌다. 초등학교 1학년 고등학교 3학년 에 재학 중인 남녀 $\mathrm{ADHD}$ 아동을 자신 및 보호자의 동의하에 연구에 포함시켰고, 웩슬러 지능검사상 지능지수가 70 이하, ${ }^{26}$ 품행장애, 반항장애, 불안장애, 우울장애 등의 공존질환들을 먼저 치료해야 할 정도로 심각한 대상자들은 연구에서 제외 시켰다. 결과적으로 총 25 명이 연구에 참여하였다. 연구대상 자들은 이미 약물치료를 받은 후 4주 이상 약물의 종류와 용 량을 변경시키지 않은 상태에서 연구에 포함되었으며, 연구기 
간 내내 약물의 종류와 용량을 변경하지 않았다.

\section{방 법}

기관윤리위원회에서 연구프로토콜의 승인(IRB No. 7001355201504-HR-053)을 받은 후 연구가 진행되었다. 대상자를 선 정한 후 훈련 전 평가가 이루어졌고, 이후 미취학아동용/소아 청소년용/성인용 CWMT 중에 대상의 연령에 적합한 소아청소 년용 CWMT가 실시되었다. ${ }^{20)}$ CWMT는 5주 동안 매회 30 45 분간 총 25 회의 훈련 세션으로 구성되었고, 훈련 세션 내 과제 의 성취도에 따라 제시되는 과제의 난이도가 자동적으로 조 절되었으며, 소정의 수련을 받아 인증을 취득한 코치 한 명에 의해 개별적으로 실시되었다. CWMT는 인지신경과학과 컴퓨 터게임 형식의 결합을 통하여 구성된 사용하기 쉬운(easy-touse) 소프트웨어에 기반하며, 전문화된 개인적인 코칭이 제공 된다는 점에서 기존의 작업기억훈련들과는 차별화된다. 이후 훈련의 효과 평가를 위해 훈련 전, 훈련 후 1 개월, 훈련 후 7 개 월의 세 시점에서 평가가 이루어졌다.

\section{평가도구}

한국판 아동행동평가척도(Korean version of Child Behavior Checklist, $\mathrm{K}-\mathrm{CBCL}$ )

Child Behavior Checklist(CBCL)는 Achenbach와 Edelbrock $^{27)}$ 이 제작한 아동의 행동평가척도이며, Korean version of CBCL(K-CBCL)은 CBCL을 우리나라에서도 사용할 수 있 도록 국내의 아동 집단을 대상으로 표준화한 행동평가척도이 다. 이후 여러 국내 표준화 및 타당성 연구가 진행되어 임상에 서 그 유용성이 입증되었다. ${ }^{28} \mathrm{~K}-\mathrm{CBCL}$ 은 크게 사회능력척도와 문제행동증후군척도로 이루어져 있고, 사회능력척도는 아동 의 전반적인 사회능력을 평가하기 위해 도입된 척도로서 아동 의 활동성, 사회성, 학업수행 등을 측정한다. 문제행동증후군 척도 안에는 위축(withdrawn), 신체증상(somatic complaints), 우울/불안(anxious/depressed), 사회적미성숙(social problems), 사고문제(thought problems), 주의력 문제(attention problems), 비행(delinquent behavior), 공격적행동(aggressive behavior), 성문제(sex problems), 정서불안정(emotional lability), 내재화문 제(internalizing problems), 외현화문제(externalizing problems), 총문제행동(total behavior problems)이 있다.

\section{한국판 아동의 건강관련 삶의 질 척도(Korean version} of KIDSCREEN-52 Quality of Life Measure for Children and Adolescents, K-KIDSCREEN-52-HRQOL)

Korean version of KIDSCREEN-52 Quality of Life Mea- sure for Children and Adolescents(K-KIDSCREEN-52$\mathrm{HRQOL}$ )는 KIDSCREEN-52-HRQOL ${ }^{29}$ 을 우리나라 실정 에 맞게 표준화한 아동의 삶의 질 평가척도이다. ${ }^{30}$ 8 18세의 아동을 대상으로 지난 7일간의 주관적인 건강과 안녕에 대해 측정하는 자가보고식 척도로서, 총 9 개 하위영역과 관련된 총 52개 문항으로 이루어져 있으며, 각각의 문항은 5점 Likert 척 도로 평정된다 $(0=$ "전혀 아니다', $1=$ "거의 아니다', $2=$ '그렇다', $3=$ '많이 그렇다', $4=$ =아주 많이 그렇다'). 하위영역에는 신체활동과 건강(5문항), 일반적인 기분(13문항), 친구들(6문항), 가족/가 정/이웃들(6문항), 자신에 대한 느낌들(5문항), 자유시간(5문 항), 학교와 공부(6문항), 괴롭힘(3문항) 및 돈문제(3문항)가 포 함된다. 아동의 삶의 질 수준은 각 문항들에 의해 평가된 점수 들의 총점을 통해 평가되며, 총점이 높을수록 아동의 건강관 련 삶의 질이 높음을 의미한다. K-KIDSCREEN-52-HRQOL 의 신뢰도는 전 하위영역에 걸쳐 Cronbach $\alpha=0.77 \sim 0.95$ 로 보 고되었다. ${ }^{30)}$

\section{한국판 부모 양육스트레스 척도-축약형(Korean version}

of Parenting Stress Index-Short Form, PSI-SF)

양육스트레스를 측정하기 위해 사용한 한국어판 Parenting Stress Index-Short Form(PSI-SF)은 Shin과 Chung ${ }^{31}$ 이 Abi$\mathrm{din}^{32}$ 의 PSI-SF를 내용이 중복되는 문항을 삭제하고 부정문 의 일부를 긍정문으로 고친 후 국내 아동을 대상으로 표준화 한 부모 보고형 척도이다. 이 척도는 3 개 요인과 관련된 20문항 으로 이루어져 있는데 요인 1은 까다로운 아동(difficult child) (8문항), 요인 2는 역기능적 상호작용(parent-child dysfunctional interaction)(9문항), 요인 3은 부모의 고충(parental distress)(3문항)이다. 각각의 문항은 '전혀 그렇지 않다' 1 점부터 '매우 자주 그렇다' 5 점까지 평정한다. 한국어판 PSI-SF의 내적 일치도는 0.94 로 보고되었다. ${ }^{31)}$

\section{통계적 분석방법}

통계적 검증은 SPSS for Windows(version 15.0; SPSS Inc., Chicago, IL, USA)를 이용하였다. 훈련의 효과를 알아보기 위하여, 훈련 전, 훈련 후 1 개월, 훈련 후 7개월의 세 평가 시점 을 피험자 내 변인으로 하여 Friedman test와 Wilcoxon signed rank test를 실시하였다. 통계적 유의수준은 $\mathrm{p}<0.05$ (양측검정) 로 하였다.

\section{결 과}

\section{인구통계학적, 진단적 특성}

본 연구 대상 아동의 인구통계학적, 진단적 특성은 Table 1 과 
Table 1. Demographic and clinical characteristics of study subjects $(n=25)$

\begin{tabular}{lc}
\hline \multicolumn{1}{c}{ Characteristics } & Mean \pm SD or $n(\%)$ \\
\hline Age (years) & $13.1 \pm 3.0$ \\
Sex (male) & $17(68.0)$ \\
IQ & $102.2 \pm 17.6$ \\
ADHD subtype & \\
Combined type & $9(36.0)$ \\
Predominantly inattentive & $16(64.0)$ \\
$\quad$ type & $0(0.0)$ \\
Predominantly hyperactive- & \\
impulsive type & \\
Comorbidities & $6(24.0)$ \\
Depressive disorder & $2(8.0)$ \\
Oppositional-defiant & \\
disorder & $1(4.0)$ \\
Conduct disorder & $4(16.0)$ \\
Learning disorder & $2(8.0)$ \\
Anxiety disorder & \\
Medications (mg/day) & $59.79 \pm 25.87(56.0)$ \\
MPH dose & $46.00 \pm 25.10(20.0)$ \\
Atomoxetine dose & $43.00 \pm 33.10,26.67 \pm 18.94(24.0)$ \\
MPH+atomoxetine dose & \\
\hline AD &
\end{tabular}

ADHD: attention-deficit hyperactivity disorder, $\mathrm{MPH}$ : methylphenidate, SD: standard deviation

같다. 아동은 총 25 명이었으며 남아 17 명, 여아 8명으로 2.1:1의

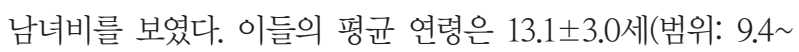

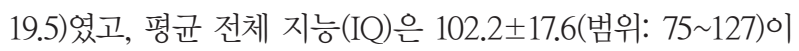
었다. $\mathrm{ADHD}$ 의 하위유형은 주의력결핍 우세형 16명(64.0\%), 복합형 9명(36.0\%)이었고, 공존질환은 우울장애 6명(24.0\%), 적대적반항장애 2명(8.0\%), 품행장애 1명(4.0\%), 학습장애 4명 (16.0\%), 불안장애 2명(8.0\%)이었다. 훈련 중 methylphenidate 를 복용한 경우는 14 명 $(56.0 \%$, 평균용량 $59.8 \mathrm{mg} / \mathrm{day})$, atomoxetine을 복용한 경우는 5명 $(20.0 \%$, 평균용량 $46.0 \mathrm{mg} / \mathrm{day})$, 둘 다 복용한 경우는 6명(24.0\%, 평균용량은 methylphenidate $43.0 \mathrm{mg} /$ day, atomoxetine $26.7 \mathrm{mg} /$ day)이었다.

\section{CWMT의 효과분석: 훈련 전, 훈련 후 1개월, 훈련 후 7개월 시점의 $\mathrm{CBCL}, \mathrm{K}-\mathrm{KIDSCREEN}-52-\mathrm{HRQOL}, \mathrm{PSI}-\mathrm{SF}$ 결과}

$\mathrm{CWMT}$ 에 의한 문제행동, 삶의 질, 부모 양육스트레스의 변 화를 비교하기 위하여 각 평가척도의 평균과 표준편차, 훈련 전, 훈련 후 1 개월, 훈련 후 7 개월, 세 시점의 Friedman test의 결과와 이에 대한 사후검증으로 실시된 Wilcoxon signed rank test의 결과를 Table 2에 제시하였다.

$\mathrm{CBCL}$ 의 사회능력 총점에서는 세 시점 간 차이가 유의하지 않았다 $\left(\chi^{2}=0.32, \mathrm{NS}\right)$. 그러나 문제행동증후군 총점에서는 세 시점 간 차이가 유의하였고 $\left(\chi^{2}=8.47, \mathrm{p}=0.015\right)$, 사후 검정 결과
훈련 전-훈련 후 1 개월 $(\mathrm{Z}=-2.24, \mathrm{p}=0.025)$, 훈련 전-훈련 후 7 개 월 $(\mathrm{Z}=-2.42, \mathrm{p}=0.016)$ 에서 유의하게 감소되었다. 사회능력 하위 척도인 사회성, 학업수행에서는 세 시점 간 차이가 유의하지 않 았다. 그러나 문제행동증후군 하위척도인 불안/우울 $\left(\chi^{2}=8.21\right.$, $\mathrm{p}=0.016)$, 사회적미성숙 $\left(\chi^{2}=10.37, \mathrm{p}=0.006\right)$, 사고문제 $\left(\chi^{2}=\right.$ $9.70, \mathrm{p}=0.008)$, 주의력 문제 $\left(\chi^{2}=6.72, \mathrm{p}=0.035\right)$ 에서는 세 시점 간 유의한 차이가 있었고, 위축, 신체증상, 비행, 공격적행동, 성문제, 정서불안정, 내재화문제, 외현화문제에서는 세 시점 간 차이가 유의하지 않았다. 사후 검정 결과, 훈련 전-훈련 후 1 개월 및 훈련 전-훈련 후 7개월에서 유의한 감소를 보인 척 도는 불안/우울 $(\mathrm{Z}=-2.42, \mathrm{p}=0.015 ; \mathrm{Z}=-2.02, \mathrm{p}=0.043)$, 사회적 미성숙 $(\mathrm{Z}=-2.29, \mathrm{p}=0.022 ; \mathrm{Z}=-1.78, \mathrm{p}=0.075)$, 주의력 문제 $(\mathrm{Z}=$ $-2.16, \mathrm{p}=0.031 ; \mathrm{Z}=-1.99, \mathrm{p}=0.046)$ 였으며, 훈련 전-훈련 후 7 개월에서만 유의한 감소를 보인 척도는 사고문제 $(\mathrm{Z}=-2.40$, $\mathrm{p}=0.017$ )였다.

$\mathrm{K}-\mathrm{KIDSCREEN}-52-\mathrm{HRQOL}$ 의 총점에서 세 시점 간 차이 가 유의하지 않았다. 또한 하위척도인 신체활동과 건강, 일반 적인 기분, 친구들, 가족/가정/이웃들, 자신에 대한 느낌들, 자 유시간, 학교와 공부, 괴롭힘, 돈문제 모두에서 세 시점 간 유 의한 차이가 관찰되지 않았다.

$\mathrm{PSI}-\mathrm{SF}$ 의 총점에서 세 시점 간 차이가 유의하지 않았으며 $\left(\chi^{2}=2.09, \mathrm{p}=0.123\right)$, 하위척도인 부모의 고충 $\left(\chi^{2}=7.36, \mathrm{p}=0.351\right)$ 과 까다로운 아동 $\left(\chi^{2}=4.19, \mathrm{p}=0.091\right)$ 에서도 세 시점 간 유의한 차이가 관찰되지 않았다. 하지만 역기능적 상호작용은 유의하 게 감소하였다 $\left(\chi^{2}=4.80, \mathrm{p}=0.025\right)$. 사후 검정 결과 역기능적 상 호작용은 훈련후 1 개월-훈련후 7개월 $(\mathrm{Z}=-1.97, \mathrm{p}=0.049)$ 및 훈련전-훈련후 7 개월 $(\mathrm{Z}=-2.80, \mathrm{p}=0.005)$ 에서 유의한 감소를 보였다.

\section{고 찰}

본 연구 결과, $\mathrm{ADHD}$ 아동 및 청소년에서 주의력 개선제 투 여 이후에도 남아 있던 문제행동들이 부가적인 작업기억훈련 을 통해 일부 호전되는 것이 관찰되었다. 현재까지 작업기억 훈련이 작업기억력과 직접적으로 관련되어 있는 부주의와 행 동조절 문제, 기타 인지기능을 변화시킨다는 사실은 보고되었 으나, 문제행동을 호전시킨다는 보고는 거의 없었다. ${ }^{33)}$ 본 연 구 결과를 통해 작업기억훈련으로 작업기억력을 향상시킴으 로써 $\mathrm{ADHD}$ 환자에서의 문제행동을 개선시킬 가능성을 확인 하였다. 이는 또한 $\mathrm{ADHD}$ 에서 우울 및 불안, 사회성 결여와 같 은 문제가 작업기억력의 부족, 즉 $\mathrm{ADHD}$ 의 핵심병리에 의한 이차적인 문제일 가능성이 높음을 시사한다. ${ }^{34,35)}$ 또한 대부분 의 $\mathrm{ADHD}$ 치료에서 약물이 가장 먼저 권고되지만 실제 약물 
치료만으로 문제행동들이 모두 개선되지 않는 경우가 적지 않 다. 저자들은 본 연구를 통해 ADHD 환자의 잔존 문제행동 을 개선하기 위해 작업기억훈련을 약물치료에 추가로 적용해 볼 수 있는 하나의 과학적 근거를 제시하였다.

작업기억훈련을 통해 다양한 행동문제들이 호전되는 기전 을 고찰해 보면, 첫째, 불안이나 우울, 주의력결핍, 사고문제의
향상은 작업기억훈련이 전전두피질의 역기능을 약화시켰기 때문으로 추측해 볼 수 있다. 우울증, $\mathrm{ADHD}$, 정신증 및 강박 증의 병리가 전전두피질의 기능부전과 관련되어 있는데, ${ }^{36)}$ 작 업기억훈련이 이 부위의 변화를 일으키는 것으로 알려져 있 다. ${ }^{15,16)}$ 이는 우울증에서 부정적 사고가 증가하는 원인이 작업 기억력의 문제 때문에 부정적 자료를 제거하지 못하기 때문이

Table 2. Changes of the K-CBCL, K-KIDSCREEN-52-HRQOL, and PSI-SF from baseline to 1 month and 7 months after training ( $\mathrm{n}=25$ )

\begin{tabular}{|c|c|c|c|c|c|c|}
\hline \multirow[b]{2}{*}{ Variables } & Baseline & Month 1 & Month 7 & \multirow[b]{2}{*}{ df } & \multirow[b]{2}{*}{$\chi^{2}$ or $Z$} & \multirow[b]{2}{*}{$\mathrm{p}$} \\
\hline & $\begin{array}{c}\text { Mean } \pm S D \\
\text { or } n(\%)\end{array}$ & $\begin{array}{c}\text { Mean } \pm S D \\
\text { or } n(\%)\end{array}$ & $\begin{array}{c}\text { Mean } \pm S D \\
\text { or } n(\%)\end{array}$ & & & \\
\hline \multicolumn{7}{|l|}{$\mathrm{K}-\mathrm{CBCL}$} \\
\hline \multicolumn{7}{|l|}{ Social competence scale } \\
\hline Social & $45.44 \pm 18.69$ & $50.28 \pm 20.82$ & $48.88 \pm 25.70$ & 2 & 0.32 & 0.852 \\
\hline School & $47.40 \pm 19.15$ & $49.60 \pm 19.47$ & $49.92 \pm 21.70$ & 2 & 0.26 & 0.878 \\
\hline Total competence scale & $42.68 \pm 18.30$ & $44.44 \pm 19.58$ & $45.72 \pm 27.41$ & 2 & 0.32 & 0.852 \\
\hline \multicolumn{7}{|l|}{ Behavior problem scale } \\
\hline Withdrawn & $56.36 \pm 8.05$ & $53.60 \pm 5.61$ & $53.80 \pm 6.86$ & 2 & 1.50 & 0.472 \\
\hline Somatic complaints & $52.56 \pm 3.51$ & $51.56 \pm 3.29$ & $52.08 \pm 3.79$ & 2 & 1.04 & 0.595 \\
\hline Anxious/depressed ${ }^{\ddagger, \|}$ & $54.56 \pm 5.51$ & $52.36 \pm 3.60$ & $52.48 \pm 4.34$ & 2 & 8.21 & $0.016^{*}$ \\
\hline Social problems ${ }^{\ddagger, \|}$ & $59.24 \pm 8.25$ & $56.36 \pm 7.90$ & $56.40 \pm 7.89$ & 2 & 10.37 & $0.006^{\dagger}$ \\
\hline Thought problems" & $57.00 \pm 6.89$ & $55.16 \pm 6.97$ & $53.32 \pm 6.34$ & 2 & 9.70 & $0.008^{\dagger}$ \\
\hline Attention problems ${ }^{\ddagger, \|}$ & $58.36 \pm 5.00$ & $55.36 \pm 6.71$ & $55.56 \pm 6.25$ & 2 & 6.72 & $0.035^{*}$ \\
\hline Delinquent behavior & $52.52 \pm 5.42$ & $52.36 \pm 3.50$ & $52.40 \pm 3.74$ & 2 & 1.14 & 0.565 \\
\hline Aggressive behavior & $54.20 \pm 5.21$ & $53.32 \pm 5.24$ & $51.60 \pm 2.84$ & 2 & 5.35 & 0.069 \\
\hline Sex problems & $51.20 \pm 4.15$ & $50.20 \pm 1.00$ & $50.96 \pm 3.43$ & 2 & 2.67 & 0.264 \\
\hline Emotional lability & $51.32 \pm 1.60$ & $50.32 \pm 1.60$ & $50.00 \pm 0.00$ & 2 & 2.00 & 0.368 \\
\hline Internalizing problem & $54.60 \pm 5.49$ & $52.32 \pm 3.77$ & $52.48 \pm 4.42$ & 2 & 3.64 & 0.162 \\
\hline Externalizing problem & $53.64 \pm 5.19$ & $53.04 \pm 4.62$ & $51.64 \pm 2.81$ & 2 & 4.75 & 0.093 \\
\hline Total behavior problem ${ }^{\ddagger, \|}$ & $54.92 \pm 4.99$ & $52.84 \pm 4.65$ & $52.20 \pm 3.83$ & 2 & 8.47 & $0.015^{*}$ \\
\hline \multicolumn{7}{|l|}{ K-KIDSCREEN-52-HRQOL } \\
\hline Physical wellbeing & $16.18 \pm 4.79$ & $17.70 \pm 4.57$ & $17.48 \pm 4.23$ & 2 & 3.75 & 0.154 \\
\hline Moods and emotions & $47.36 \pm 10.56$ & $46.70 \pm 10.40$ & $49.35 \pm 11.57$ & 2 & 3.21 & 0.201 \\
\hline Social support and peers & $21.05 \pm 6.28$ & $22.74 \pm 10.32$ & $22.30 \pm 6.40$ & 2 & 0.58 & 0.747 \\
\hline Parent relations and home life & $22.09 \pm 5.49$ & $23.26 \pm 5.48$ & $23.48 \pm 4.85$ & 2 & 4.59 & 0.101 \\
\hline Self-perception & $19.14 \pm 3.41$ & $20.22 \pm 3.81$ & $19.22 \pm 3.77$ & 2 & 2.76 & 0.252 \\
\hline Autonomy & $16.64 \pm 4.87$ & $17.30 \pm 5.45$ & $16.65 \pm 5.67$ & 2 & 2.31 & 0.314 \\
\hline School environment & $21.55 \pm 6.31$ & $22.70 \pm 4.68$ & $22.35 \pm 5.12$ & 2 & 1.40 & 0.497 \\
\hline Social acceptance (bullying) & $12.95 \pm 2.19$ & $13.61 \pm 1.97$ & $13.54 \pm 2.11$ & 2 & 0.31 & 0.856 \\
\hline Financial resources & $9.18 \pm 3.71$ & $10.17 \pm 3.24$ & $10.18 \pm 3.46$ & 2 & 1.94 & 0.380 \\
\hline Total quality of life & $186.14 \pm 33.04$ & $194.39 \pm 32.21$ & $195.77 \pm 34.20$ & 2 & 3.60 & 0.165 \\
\hline \multicolumn{7}{|l|}{ PSI-SF } \\
\hline Parental distress & $30.60 \pm 6.49$ & $28.79 \pm 7.16$ & $27.56 \pm 7.43$ & 2 & 7.36 & 0.351 \\
\hline Parent-child dysfunctional interaction ${ }^{\S, \|}$ & $31.16 \pm 7.21$ & $29.17 \pm 6.82$ & $26.84 \pm 7.43$ & 2 & 4.80 & $0.025^{*}$ \\
\hline Difficult child & $38.16 \pm 6.99$ & $38.63 \pm 8.39$ & $40.96 \pm 7.12$ & 2 & 4.19 & 0.091 \\
\hline Total stress & $99.72 \pm 9.55$ & $96.58 \pm 13.95$ & $96.16 \pm 10.33$ & 2 & 2.09 & 0.123 \\
\hline
\end{tabular}

${ }^{*} p<0.05,{ }^{\dagger} p<0.01$, ${ }^{\ddagger}$ Friedman test with post-hoc Wilcoxon singed rank test revealed significant difference in mean rank reduction from baseline to 1 month after training, \&Friedman test with post-hoc Wilcoxon singed rank test revealed significant difference in mean rank reduction from 1 month to 7 months after training, "Friedman test with post-hoc Wilcoxon singed rank test revealed significant difference in mean rank reduction from baseline to 7 months after training. K-CBCL: Korean version of Child Behavior Checklist, K-KIDSCREEN-52-HRQOL: Korean version of KIDSCREEN-52 Quality of Life Measure for Children and Adolescents, PSI-SF: Parental Stress Index-Short Form, SD: standard deviation 
라는 기존 연구 결과와도 연관성이 있으며,(4) 정신증 환자에서 작업기억력훈련을 통해 작업기억력의 향상과 ${ }^{37)}$ 뇌 활성의 변 화를 보고한 기존 연구 결과와도 연관성이 있다. ${ }^{38)}$ 둘째, 사회 성 문제의 감소는 작업기억력 향상의 일차적 효과로 보기보 다는 훈련에 의한 정서조절 능력의 향상에 따른 이차적 효과 로 생각해 볼 수 있다. 작업기억력과 정서조절 능력을 담당하 는 신경망이 전두-두정엽의 '다중 요구 망(multiple-demand network)'에서 공유된다는 연구 결과 ${ }^{35)}$ 는 이러한 가설을 지지 해준다. 셋째, 본 연구에서는 통계적 유의성을 보이지는 않았 고 경향성 $(\mathrm{p}=0.069)$ 만 관찰되기는 했지만, 작업기억훈련이 공 격성을 감소시킬 가능성도 있다. 작업기억력 향상이 억제력을 증가시켜 사회적 정보처리가 원활해지고 결국 공격성과 반사 회적 행동이 줄어들 수 있기 때문이다. ${ }^{39}$

흥미롭게도 $\mathrm{ADHD}$ 아동 및 청소년의 행동에 미치는 작업 기억훈련의 효과는 문제행동의 종류에 따라 시간적 차이가 관찰되었다. 즉 전반적인 문제행동, 불안과 우울, 사회성 문제 와 주의력 문제는 훈련 직후에 바로 유의하게 감소하였고, 그 효과는 훈련 후 7 개월까지 지속되었다. 반면 사고의 문제는 훈련 직후에는 변화가 없다가 7개월이 지나서야 효과가 나타 나는 장기간의 지연효과가 관찰되었다. 이러한 연구 결과는 CWMT를 이용한 선행연구 결과와도 일치하는 소견이다. ${ }^{40)}$ 이러한 시간적 차이가 발생한 이유를 고찰해 보면, 첫째, 본 연구에 참여한 환자군의 특성 때문일 수 있다. 본 연구에서는 $\mathrm{ADHD}$ 아형 중 부주의 우세형이 64\%가 포함되어 있어 일반 적인 $\mathrm{ADHD}$ 군에 비해 불안, 우울 등의 내재화문제가 외현화 문제보다 더 두드러질 가능성이 있다. ${ }^{41)}$ 또한 공존질환의 빈 도도 우울장애와 불안장애(32\%)가 도전적반항장애와 행실장 애(12\%)보다 우세하였다. 따라서 훈련에 의해 작업기억력이 향상되면서 핵심증상인 주의력 문제가 호전되고, 이후에 주 를 이루는 불안/우울이 먼저 호전되었을 가능성이 있다. 둘째, CWMT 이후 과잉행동/충동성 증상이 주의력결핍 증상보다 덜 좋아지는 경향이 있는데, ${ }^{20)}$ 이는 작업기억훈련이 과잉행 동/충동성과 관련성이 깊은 외현화문제에는 효과가 덜할 가 능성을 시사하며, 본 연구 결과와도 연관성이 있다. 추후 외현 화문제가 자주 동반되거나 과잉행동/충동성 증상이 심각한 $\mathrm{ADHD}$ 를 충분히 포함시킨 연구를 통해 검증해 볼 필요가 있 다. 셋째, 작업기억력훈련의 전이효과를 매개하는 요인으로써 우울/불안 증상과 연관이 많은 내적 동기 및 자기-지각 인지 결 손(self-perceived cognitive deficit)이 중요하다는 최근 보고 들도 본 연구 결과를 지지한다. ${ }^{42,43}$ 넷째, Van Nieuwenhuijzen 등 ${ }^{39)}$ 은 실행기능 중 억제기능과 초점주의력의 손상이 공격성 의 선택과정과 연관되어 있다고 주장했는데, 작업기억력이 향 상되면서 초점주의력이 먼저 향상되고 이것이 억제력을 증가
시켜, 결국 공격성을 감소시켰을 가능성이 시사된다. 이는 작업 기억력의 향상이 공격성의 감소에 이르기까지 일정한 시간이 필요하다는 본 연구 결과를 지지하는 소견이다.

$\mathrm{ADHD}$ 아동 및 청소년의 부모들은 작업기억력훈련의 결과 아동과의 역기능적 상호작용과 관련된 부모의 양육스트레스 가 감소되었다. 이는 $\mathrm{ADHD}$ 에서 약물치료를 통해 부모의 양 육스트레스 감소로 이어진다는 기존의 연구 결과와 부분적 으로 일치하는 소견이다. ${ }^{44}$ 하지만 본 연구에서는 부모의 양육 스트레스가 훈련 전-훈련 후 1개월까지는 감소하지 않다가 훈 련 후 1 개월과 7개월 사이에 유의하게 감소하는 지연효과를 나타냈다. 이는 아동 및 청소년에게 훈련효과가 먼저 나타난 후 이후 부모와의 상호작용에 긍정적인 경험이 일어나기까지 어느 정도 시간이 소요됨을 의미한다. 이는 수학학습능력이 작 업기억훈련 직후에는 변화가 없다가 6개월 이후에 지연 향상된 기존 연구 결과와도 일치하는 소견이다. ${ }^{45}$

$\mathrm{ADHD}$ 아동 및 청소년은 작업기억력훈련의 결과 자신의 삶 의 질이 개선되었다고 보고하지 않았다. 삶의 질이라는 개념 은 다차원적이며, 객관적 증상이나 기능 수준과는 구별되게 주관적 측면을 반영하는 개념이기 때문에, ${ }^{46}$ 본 연구의 결과로 작업기억력훈련이 아동의 삶의 질에 효과가 없다고 단정짓는 것은 섣부르다. 추후 연구에서 삶의 질에 대한 다각도의 척도 를 활용하거나, 아동이 주관적으로 질병 및 훈련을 어떻게 받 아들이는지 등을 더 고려하여 검증해 볼 필요성이 있다.

이상의 결과들을 종합해 볼 때, CWMT는 약물치료를 받고 있는 ADHD 아동 및 청소년에게 아직도 남아 있는 행동문제 와 부모의 일부 양육스트레스 감소에도 도움이 되는 유용한 개입이 될 수 있다. 또한 이러한 효과는 훈련 후 7개월까지 지 속되었고, 일부는 지연효과를 나타낼 수도 있음이 관찰되었 다. 하지만 본 연구는 대상자 수가 비교적 적다는 점, 단일 센 터에 내원하는 아동만을 대상으로 했다는 점, 통제 집단과의 비교가 이루어지지 못하여 치료자의 관심 변인 등 다른 변인 의 영향을 통제하지 못했던 점 등에서 제한점이 있다. 앞으로 이를 보완한 후속 연구가 필요하다.

\section{결 론}

본 연구 결과, CWMT는 약물치료로 충분히 좋아지지 않은 $\mathrm{ADHD}$ 아동 및 청소년의 불안/우울, 사회적미성숙, 주의력 문 제를 비롯한 문제행동을 호전시켰으며, 부모의 양육스트레스 도 감소시켰다. 이러한 효과는 훈련 후 7개월까지 유지되었다.

중심 단어:작업기억력훈련; 코드메드;

주의력결핍 과잉행동장애; 행동문제; 부모스트레스. 


\section{Conflicts of Interest}

The authors have no financial conflicts of interest.

\section{REFERENCES}

1) Banh GH. Attention-deficit hyperactivity disorder. Drug Infrmation 2009;35:14-23.

2) Martinussen R, Hayden J, Hogg-Johnson S, Tannock R. A metaanalysis of working memory impairments in children with attention-deficit/hyperactivity disorder. J Am Acad Child Adolesc Psychiatry 2005;44:377-384

3) Diamond A. Executive functions. Annu Rev Psychol 2013;64:135168.

4) Doyle AE. Executive functions in attention-deficit/hyperactivity disorder. J Clin Psychiatry 2006;67 Suppl 8:21-26.

5) Solanto MV. Neuropsychopharmacological mechanisms of stimulant drug action in attention-deficit hyperactivity disorder: a review and integration. Behav Brain Res 1998;94:127-152.

6) Tannock R, Schachar RJ, Carr RP, Chajczyk D, Logan GD. Effects of methylphenidate on inhibitory control in hyperactive children. J Abnorm Child Psychol 1989;17:473-491.

7) A 14-month randomized clinical trial of treatment strategies for attention-deficit/hyperactivity disorder. The MTA Cooperative Group. Multimodal Treatment Study of Children with ADHD. Arch Gen Psychiatry 1999;56:1073-1086.

8) MTA Cooperative Group. National Institute of Mental Health Multimodal Treatment Study of ADHD follow-up: changes in effectiveness and growth after the end of treatment. Pediatrics 2004;113:762769.

9) Molina BS, Hinshaw SP, Swanson JM, Arnold LE, Vitiello B, Jensen PS, et al. The MTA at 8 years: prospective follow-up of children treated for combined-type ADHD in a multisite study. J Am Acad Child Adolesc Psychiatry 2009;48:484-500.

10) Prince JB. Pharmacotherapy of attention-deficit hyperactivity disorder in children and adolescents: update on new stimulant preparations, atomoxetine, and novel treatments. Child Adolesc Psychiatr Clin N Am 2006;15:13-50.

11) Chronis AM, Jones HA, Raggi VL. Evidence-based psychosocial treatments for children and adolescents with attention-deficit/hyperactivity disorder. Clin Psychol Rev 2006;26:486-502.

12) Park MY, Park SM, Cho SZ, Shin MS. The effect of CBT-based training using computer games for ADHD children. Korean J Clin Psychol 2010;29:639-657.

13) Kim JI, Yoon S, Oh HK, Lee SH. Clinical significance for neurofeedback training of children with attention-deficit/hyperactivity disorder. J Korean Neuropsychiatr Assoc 2015;54:62-68.

14) Silverman WK, Hinshaw SP. The second special issue on evidencebased psychosocial treatments for children and adolescents: a 10year update. J Clin Child Adolesc Psychol 2008;37:1-7.

15) Olesen PJ, Westerberg H, Klingberg T. Increased prefrontal and parietal activity after training of working memory. Nat Neurosci 2004; 7:75-79.

16) McNab F, Varrone A, Farde L, Jucaite A, Bystritsky P, Forssberg H, et al. Changes in cortical dopamine D1 receptor binding associated with cognitive training. Science 2009;323:800-802.

17) Söderqvist S, Bergman Nutley S, Peyrard-Janvid M, Matsson H, Humphreys K, Kere J, et al. Dopamine, working memory, and training induced plasticity: implications for developmental research. Dev Psychol 2012;48:836-843.

18) Brehmer Y, Westerberg H, Bellander M, Fürth D, Karlsson S, Bäckman L. Working memory plasticity modulated by dopamine transporter genotype. Neurosci Lett 2009;467:117-120.

19) Klingberg T, Forssberg H, Westerberg H. Training of working memory in children with ADHD. J Clin Exp Neuropsychol 2002;24:781791.
20) Klingberg T, Fernell E, Olesen PJ, Johnson M, Gustafsson P, Dahlström K, et al. Computerized training of working memory in children with ADHD--a randomized, controlled trial. J Am Acad Child Adolesc Psychiatry 2005;44:177-186.

21) Holmes J, Gathercole SE. Taking working memory training from the laboratory into schools. Educ Psychol (Lond) 2014;34:440-450.

22) Dunning DL, Holmes J, Gathercole SE. Does working memory training lead to generalized improvements in children with low working memory? A randomized controlled trial. Dev Sci 2013;16: 915-925.

23) van Dongen-Boomsma M, Vollebregt MA, Buitelaar JK, SlaatsWillemse D. Working memory training in young children with ADHD: a randomized placebo-controlled trial. J Child Psychol Psychiatry 2014;55:886-896.

24) Green CT, Long DL, Green D, Iosif AM, Dixon JF, Miller MR, et al. Will working memory training generalize to improve off-task behavior in children with attention-deficit/hyperactivity disorder? Neurotherapeutics 2012;9:639-648.

25) Bergman-Nutley S, Klingberg T. Effect of working memory training on working memory, arithmetic and following instructions. Psychol Res 2014;78:869-877.

26) Korean Education Development Institute. Mannual for KEDI-WISC. Seoul: Special Education Publishers;1991.

27) Achenbach TM, Edelbrock CS. Manual for the child behavior checklist and revised behavior profile. Burlington: University of Vermont; 1983.

28) Han MH, Yoo AJ. The validation of the Child Behavior Checklist. Korean J Child Stud 1995;16:5-21.

29) Ravens-Sieberer U, Gosch A, Rajmil L, Erhart M, Bruil J, Duer W, et al. KIDSCREEN-52 Quality-of-Life Measure for Children and Adolescents. Expert Rev Pharmacoecon Outcomes Res 2005;5:353364.

30) Hong SD, Yang JW, Jang WS, Byun H, Lee MS, Kim HS, et al. The KIDSCREEN-52 Quality of Life Measure for Children and Adolescents (KIDSCREEN-52-HRQOL): reliability and validity of the Korean version. J Korean Med Sci 2007;22:446-452.

31) Shin SJ, Chung MJ. Effects of stress, social support and efficacy on mothers' parenting behaviors. Korean J Child Stud 1998;19:27-42.

32) Abidin RR. Parenting Stress Index Short Form. Charlottesville: Pediatric Psychology Press; 1995.

33) Söderqvist S, Nutley S. Cogmed working memory training: claims \& evidence-extended version [cited 2015 Nov 1]. Available from: http://www.cogmed.com/wp-content/uploads/CogmedClaimsEvidence.pdf.

34) Joormann J, Gotlib IH. Updating the contents of working memory in depression: interference from irrelevant negative material. J Abnorm Psychol 2008;117:182-192.

35) Duncan J. The multiple-demand (MD) system of the primate brain: mental programs for intelligent behaviour. Trends Cogn Sci 2010; 14:172-179.

36) Ansari $S$. The therapeutic potential of working memory training for treating mental disorders. Front Hum Neurosci 2015;9:481.

37) Subramaniam K, Luks TL, Garrett C, Chung C, Fisher M, Nagarajan $\mathrm{S}$, et al. Intensive cognitive training in schizophrenia enhances working memory and associated prefrontal cortical efficiency in a manner that drives long-term functional gains. Neuroimage 2014; 99:281-292.

38) Li X, Xiao YH, Zhao Q, Leung AW, Cheung EF, Chan RC. The neuroplastic effect of working memory training in healthy volunteers and patients with schizophrenia: implications for cognitive rehabilitation. Neuropsychologia 2015;75:149-162.

39) Van Nieuwenhuijzen M, Van Rest MM, Embregts PJ, Vriens A, Oostermeijer S, Van Bokhoven I, et al. Executive functions and social information processing in adolescents with severe behavior problems. Child Neuropsychol 2017;23:228-241. 
40) Beck SJ, Hanson CA, Puffenberger SS, Benninger KL, Benninger WB. A controlled trial of working memory training for children and adolescents with ADHD. J Clin Child Adolesc Psychol 2010;39:825836.

41) Wolraich ML, Hannah JN, Pinnock TY, Baumgaertel A, Brown J. Comparison of diagnostic criteria for attention-deficit hyperactivity disorder in a county-wide sample. J Am Acad Child Adolesc Psychiatry 1996;35:319-324.

42) Au J, Sheehan E, Tsai N, Duncan GJ, Buschkuehl M, Jaeggi SM. Improving fluid intelligence with training on working memory: a meta-analysis. Psychon Bull Rev 2015;22:366-377.

43) Jaeggi SM, Buschkuehl M, Jonides J, Perrig WJ. Improving fluid intelligence with training on working memory. Proc Natl Acad Sci
U S A 2008;105:6829-6833.

44) Kim JW, Park S, Kim BN, Shin MS, Cho SC, Kim JH, et al. Parental perceived benefits of OROS-methylphenidate treatment for the child with attention-deficit/hyperactivity disorder and for parents themselves. Pharmacopsychiatry 2013;46:137-146.

45) Holmes J, Gathercole SE, Dunning DL. Adaptive training leads to sustained enhancement of poor working memory in children. Dev Sci 2009;12:F9-F15.

46) Revicki DA, Osoba D, Fairclough D, Barofsky I, Berzon R, Leidy NK, et al. Recommendations on health-related quality of life research to support labeling and promotional claims in the United States. Qual Life Res 2000;9:887-900. 